\title{
Development of Polyolefin Compound and Post -Polymerization Treatments for Ground Heat Exchangers
}

\author{
Adib Kalantar Mehrjerdi ${ }^{1}$, Sébastien Naudin², Mikael Skrifvars ${ }^{1}$
}

${ }^{1}$ Swedish Centre for Resource Recovery, University of Borås, 50190 Borås, Sweden

2 Eco-Design in Polymers and Composites, University of South Brittany, 56100 Lorient, France

\begin{abstract}
A ground source heat pump (GSHP) system can be used for both cooling and heating modes simultaneously for commercial, industrial and residential buildings virtually at any location with great flexibility to cover a wide range of demands all around the world. Polyetbylene (PE) has been used as the main raw material in production of the Ground Heat Exchangers (GHE). This paper briefly reviews the history of polyethylene and development in polymerization process with emphasis on the third-generation bimodal structure. The characteristics of PE pipes used in GSHP systems are discussed. This paper is devoted to a critical review on the attempts in post-polymerization treatments of the PE, and GHEs to improve the performance of the systems. The experimental and simulated comparisons show that the enhancement of the thermal conductivity of the material can reduce significantly the overall borehole thermal resistance.
\end{abstract}

\section{INTRODUCTION}

Geothermal energy is an energy source known for a long time, but with development of recent materials and techniques has had an improvement due to its renewable nature. Near-surface geothermal energy consists of exploiting the thermal inertia of the ground to gather heat in winter and reject heat to ground in summer. A fluid (e.g. glycol/water mixture) transfers the heat from the ground to the heating system. This geothermal energy method works using a heat pump in which the fluid circulates in the heat system consisting of collector pipes, circulation pumps, plate heat exchangers and refrigerant liquids. The collectors are commonly made of polyethylene (Syndicat, 2012). Studies show that ground coupled heat pump systems are potentially more efficient than traditional air-air heat pump systems (Spitler, Rees, \& Yavuzturk, 2000). The most common configuration is the vertical mode, which has the collector pipes in a borehole held either with a backfilling material similar to concrete or without any backfilling material with direct contact to the ground water. The efficiency of the borehole depends on the conductive and convective resistance of the fluid, the pipe, the backfilling material and the ground conditions. One of the important components in the system is the Ground Heat Exchangers (GHE) which are most often made from High Density Polyethylene (HDPE). Many attempts have been made to reduce the thermal resistance of the borehole but only few 
have aimed at enhancing the properties of the GHE to diminish borehole resistance. Therefore, this paper briefly reviews the history of polyethylene (PE) and development in polymerization processes with emphasis on the thirdgeneration bimodal architecture. Then, the efforts that have been reported in the literature, to enhance the performance of the GHEs will be discussed and analyzed. Finally, a numerical tool was used to simulate the performance of the GHEs. Dedicated software, Earth Energy Designer (EED) version 3.22 was used to computationally model the evolution of the effective borehole thermal resistance and borehole length (Hellström, \& Sanner, 2016).

\section{POLYETHYLENE}

$\mathrm{PE}$ is the most commonly used polymer around the world in many applications and is the simplest hydrocarbon polymer. It was discovered in 1898 by accident by the German chemist Hans von Pechmann. In 1933, Reginald Gibson and Eric Fawcett discovered the synthesis of industrially practical PE, at the Imperial Chemical Industries in Northwich, England (Visakh \& Lüft, 2016). The most stable staggered conformation is presented in Figure 1. Several types of PE exist as depending on the application. General speaking, there are two macromolecular factors that govern the final properties of a PE compound. The first is the length of the molecule that is proportional to $\mathrm{n}$ (Figure 1) and the second is the shape of the molecule for example the presence of side branching. The synthesis of PE has evolved considerably from 1933 to the present with the development of processes, catalysts and additives. These developments led to the synthesis of PE with different lengths of chains, degrees of crystallinity, molecular mass distribution and short or long side branching and, by that technique different properties to accommodate specific needs.

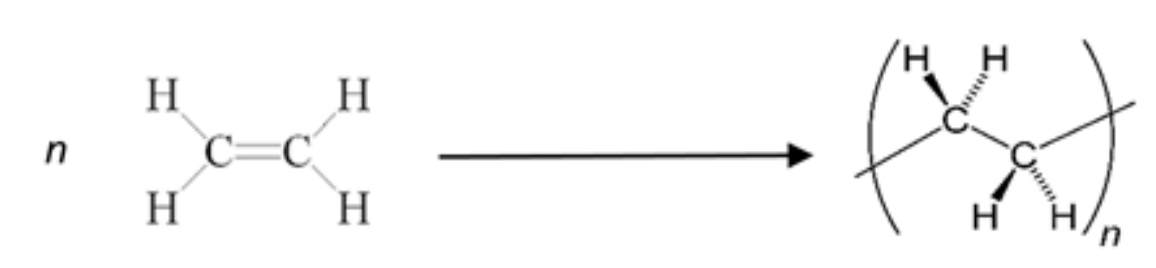

Figure 1 Polymerization of ethylene into polyethylene

\section{Polymerization process}

Polyethylene is produced by reacting gaseous ethylene monomers $\left(\mathrm{CH}_{2}-\mathrm{CH}_{2}\right)$ to obtain chains of $\left(-\mathrm{CH}_{2}-\mathrm{CH}_{2}-\right) \mathrm{n}$ with various values of $\mathrm{n}$ until over $3,000,000 \mathrm{~g} / \mathrm{mol}$ (Figure 1). Ethylene is highly reactive and must be of high purity, with very low amounts of moisture, oxygen and other alkenes. This monomer is commonly produced from petroleum but can also be bio-based and made from dehydration of ethanol (for example from sugar beet or sugar cane). Since the polymer forms on the surface of the catalyst in the reactor, the temperature and pressure in the reactor and the type of catalyst govern the final molecular architecture. In fact, the nature of the catalyst and the reactor conditions control the structure as well as, the crystallinity and the mechanical properties of the polymer (Peacock, 2000). Figure 2 shows the three major types of PE. Low density polyethylene (LDPE) is produced by free radical polymerization of ethylene initiated by organic peroxides at high pressure and high temperature. The other types of PE are produced using catalysts under milder conditions. 


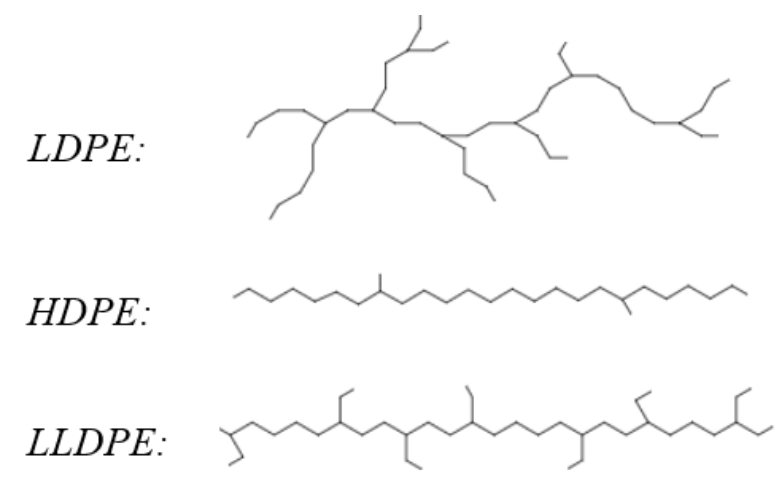

Figure 2 Schematic microstructure of major types of polyethylene showing main chains, short-chain branches and long-chain branches. Top; Low Density Polyethylene (LDPE) Middle; High Density Polyethylene (HDPE) Bottom; Linear Low Density Polyethylene (LLDPE)

PE grades (regardless of production methods), are usually classified by their density, which also includes the ratio of crystallized $\left(1.00 \mathrm{~g} / \mathrm{cm}^{3}\right)$ and amorphous fractions $\left(0.86 \mathrm{~g} / \mathrm{cm}^{3}\right)$, as illustrated in Figure 3. The scale goes from LDPE with a density of approximately $0.915-0.930 \mathrm{~g} / \mathrm{cm}^{3}$ to HDPE with densities around $0.940-0.958 \mathrm{~g} / \mathrm{cm}^{3}$ (Malpass, 2010).

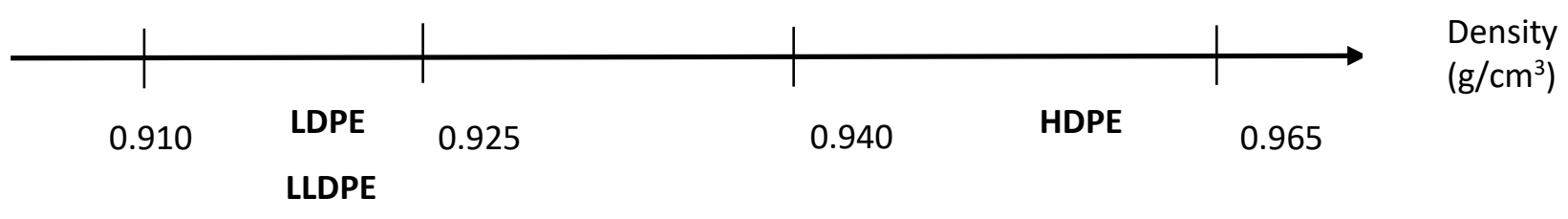

Figure 3 Density of the main grades of polyethylene

\section{PIPE APPLICATIONS}

The first PE pipes were introduced to the market as early as the 1940's with the commercialization of the PE materials. Because of the continuous development of PE materials, the efficiency of PE pipes and fittings have been improved considerably. PE pipes for pressure pipe applications are no longer classified by their density, and are now ordered into minimum required strength (MRS) classes based on the international standard ISO 9080. There have been 3 generations of PE pipes. The first PE pipes was produced from LDPE and from Medium Density Polyethylene. These are commonly known as 1 PE 32 and PE 63 in which the digits show the MRS class. The second generation of PE pipe (named PE 80) was made by a unimodal distribution type PE and mostly used for gas distribution. The last and current generation PE pipe is made from a bimodal distribution PE known as PE 100. (Brömstrup, 2009). The polymerization is done using a multi-reactor technology to obtain a tailored material, controlling the molecular weight distribution (Vasile \& Pascu, 2005). It is difficult to make a unimodal polymer with a desired set of properties and a shift in the molecular weight or molecular weight distribution (MWD) may improve one property, but may also compromise another. One solution to overcome this problem is to produce PE with a bimodal/multimodal MWD. The goal of bimodal MWD technology is to associate low and high molecular weight components in different concentration by using two series reactors (or multi connected reactors), each of which performs specific sub-process. The low molecular weight fraction is polymerized in the first reactor to bring processability properties and stiffness. This fraction has short un-branched chains with a high crystallinity degree that 
provides high density. Then, in the second reactor, a co-monomer is added in the presence of ethylene and hydrogen to produce a co-polymer with low crystallinity, forming in situ blends of the two polymer fractions. The longbranched chains provide low density and stress crack resistance to the polymer.

Bimodal PE is designed to resist slow crack fracture and to withstand any application of high pressure pipe (Brömstrup, 2009). Consequently, these grades permit production of thinner products with the same operating pressure and compare to unimodal PE, production cost is lower. Failure in PE pipes could happen over a long term under low stress (under the yield stress). The resistance to this phenomenon is the environmental stress-cracking resistance or slow crack resistance (SCR). The SCR of bimodal PE is more than three times that of some unimodal PE grades. The high SCR in bimodal PE is due to the chain entanglements obtained with the incorporation of comonomers in the polymer of the high molecular weight fraction. These entanglement networks affect the overall mechanical behavior under low stress conditions. The failure includes several stages. Microscopic cavities are formed around inhomogeneities such as scratches, pigments, catalyst residues, fillers and then these cavities form the initiation crazing step. It takes the largest fraction of the failure mechanism. Once the deformation zone is formed, crazes propagate by the disentanglement of macromolecules and plastic deformation (yielding) until a crack initiation (Kissin, 2013). Then the crack propagates until material failure. Typical properties of the two grades of PE pipes are shown in Table 1.

Table 1. Properties for Two PE Pipe Grades

\begin{tabular}{llcc}
\hline \multicolumn{1}{c}{ Characteristic } & \multicolumn{1}{c}{ Standard } & PE 80 & PE 100 \\
\hline \hline Minimum Required Strength, MRS & EN ISO 9080 & $8 \mathrm{MPA}$ & $10 \mathrm{MPa}$ \\
Density at $23^{\circ} \mathrm{C}$ & ISO 1180 & $0.94 \mathrm{~g} / \mathrm{cm}^{3}$ & $0.95 \mathrm{~g} / \mathrm{cm}^{3}$ \\
Melt flow rate (MFR) & ISO 1133 & $\pm 20 \% \mathrm{RM}$ & $\pm 20 \% \mathrm{RM}$ \\
Min. tensile strength & ISO 6259 & $15 \mathrm{MPa}$ & $19 \mathrm{MPa}$ \\
Elongation at break & ISO 6259 & $350 \%$ & $350 \%$ \\
Oxidation induction time - OIT & ISO $11357-6$ & $720 \mathrm{~min}$ & $>20 \mathrm{~min}$ \\
Hydrostatic strength $20^{\circ} \mathrm{C}, 100 \mathrm{~h}$ & EN ISO 1167 & $10 \mathrm{MPa}$ & $12.4 \mathrm{MPa}$ \\
Hydrostatic strength $80^{\circ} \mathrm{C}, 165 \mathrm{~h}$ & EN ISO 1167 & $4.6 \mathrm{MPa}$ & $5.5 \mathrm{MPa}$ \\
Hydrostatic strength $80^{\circ} \mathrm{C}, 1000 \mathrm{~h}$ & EN ISO 1167 & $4 \mathrm{MPa}$ & $5 \mathrm{MPa}$ \\
& & & \\
\hline
\end{tabular}

\section{POST POLYMERIZATION AND GROUND HEAT EXCHANGERS}

The need for new polymer materials for specific purposes has been grown in recent years because the currently synthesized polymers do not satisfy the increasing demands of many new applications. Though more and more polymers are synthesized they cannot fulfill all the specifications for many fast-growing applications, therefore post polymerization has become an attractive method to fill the gap. Polymer blends and polymer composites are two major approaches for post polymerization modification. Polymer blends are mixtures of structurally different polymers to broaden the range of properties and applications offered by the polymers. In contrast, commercial thermoplastics are commonly compounded with fillers to improve targeted properties, such as rigidity, strength, hardness, dimensional stability, electrical and thermal conductivity or crystallinity. Many particles and fibers have been compounded with polymers, such as metals, carbon fibers, glass fibers, and ceramics, each of which given different qualities and properties for the intended end-use. The most common fillers are minerals such as calcium carbonate, glass spheres, carbon black, clay, mica and talc (Wypych, 2009). Carbon black (CB) has been used as an economical additive in many thermoplastic and thermoset compounds; it is also a very effective additive for the improvement of plastics outdoor stability. It has been shown that for HDPE/CB mixtures, even at a level of $0.05 \%$-wt $\mathrm{CB}$, the composite has very good UV-resistance and this can be enhanced further by adding up to $5 \%$-wt CB (White, \& Turnbull, 1994). The most commonly used plastics, such as LDPE and HDPE, are considered thermal insulators with low thermal conductivity. There are many new applications such as electronic packaging, pipe networks, heat 
exchangers, and domestic appliances, in which an increase in the heat transfer properties would be an advantage.

Ground source heat pump systems are exceptionally efficient in cooling and heating modes for commercial, industrial and residential buildings all around the world. The amount of heat that can be transferred between the ground and the GHE depends on the thermal conductivity of the ground and on the borehole thermal resistance. The quality of the ground depends on the local geological properties and cannot as such be tuned, but the quality of the boreholes can be engineered to reduce the thermal resistance. The overall borehole thermal resistance can have a significant effect on the system performance and therefore should be kept as low as possible. The overall borehole thermal resistance depends on many factors such as the borehole diameter, the type of backfilling, the convective heat transfer between fluid and GHE, the fluid characteristics, and the position and thermal conductivity of the GHE. The pipe thermal resistance can be expressed under quasi-steady state conditions (Sundén, 2012) by equation 1:

$$
R_{p i p e}=\left(\ln \left(r_{2} / r_{1}\right)\right) / 2 \pi k
$$

Where $\mathrm{k}$ is the pipe thermal conductivity and $\mathrm{r}_{2}$ and $\mathrm{r}_{1}$ are the pipe outer and inner radius respectively. Figure 4 plots the above relationship for the pipe thermal resistance against the thermal conductivity of the material in the range of polymers-thermal conductivity. As it can be seen from this figure and equation, pipe thermal resistance depends strongly on the thermal conductivity and the standard dimension ratio (SDR, the ratio between pipe diameter and thickness) of the pipe. However, increasing the thermal conductivity of the material above $2 \mathrm{~W} / \mathrm{m} . \mathrm{K}$, the decrease in pipe thermal resistance is small. This figure also emphasizes that the pipe thermal resistance is a significant portion of the overall borehole resistance so any efforts to decrease the pipe thermal resistance are appreciated. The thermal conductivity of most HDPE grades is about $0.4 \mathrm{~W} / \mathrm{m} . \mathrm{K}$.

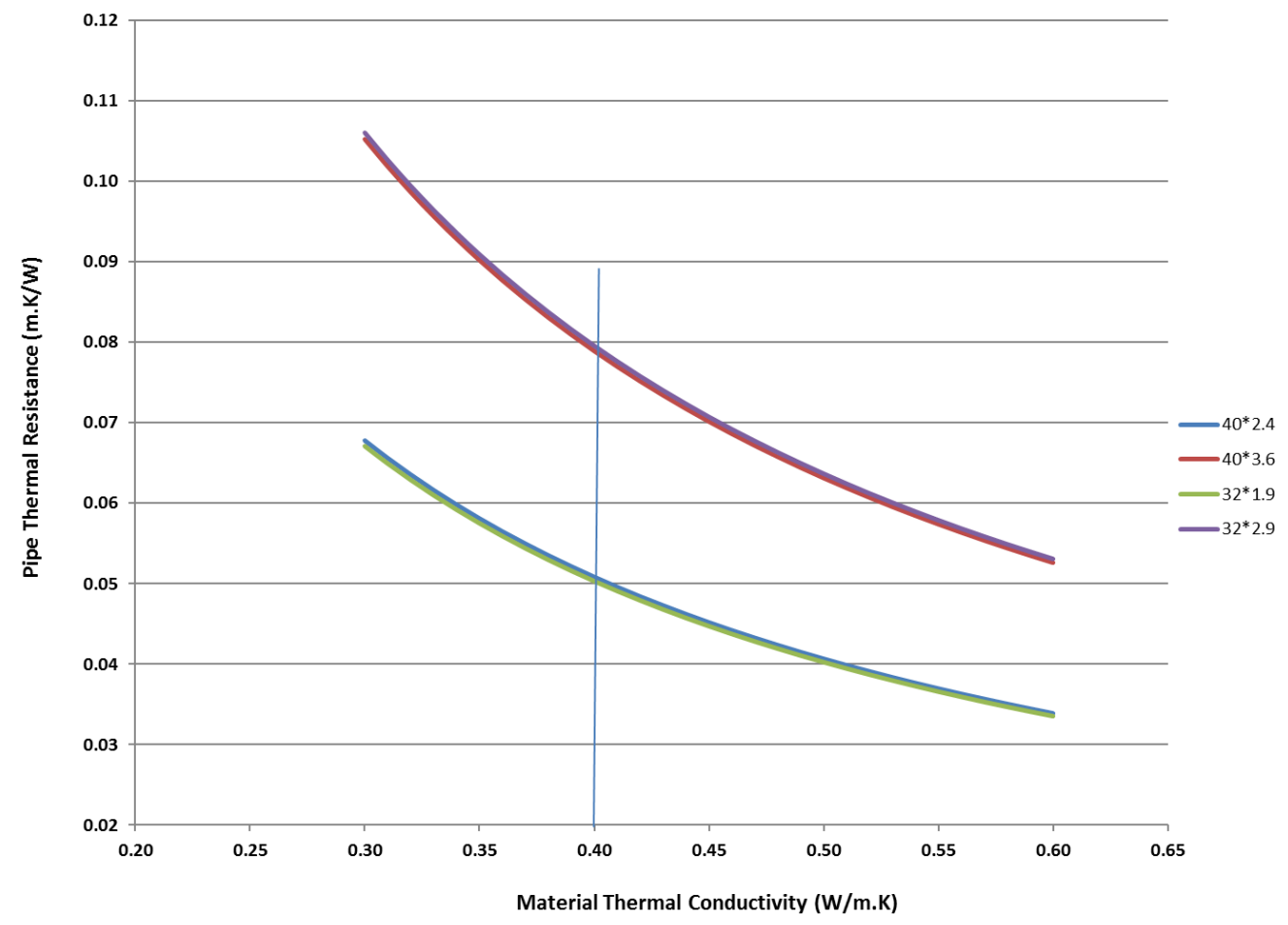

Figure 4 Pipe thermal resistance vs thermal conductivity of pipe material, top two pipes with SDR 11 and bottom two pipes with SDR 17. The legend shows outside dimeter* pipe wall thickness. 
To the best of the authors' knowledge, there are currently two attempts that focus exclusively on enhancing the thermal conductivity of GHE by post-polymerization treatments and compounding. One thermally conductive HDPE material is introduced to the market commercially called Geoperformx (Versaprofiles, 2016), and the other conductive PE composite was patented by MuoviTech Group (Kalantar \& Skrifvars, 2013). According to the data sheet and information from Versaprofile, the thermal conductivity of the Geoperformx is about $0.7 \mathrm{~W} / \mathrm{m} .{ }^{\circ} \mathrm{K}$. However, in the literature there is no further information about other properties of this material. A thermogravimetric analysis (TGA) was done with a TA instrument Q 500 supplied by Waters LLC, New Castle, IN, USA. Sample of 10 $\pm 3 \mathrm{mg}$ from the pipe were heated at $10^{\circ} \mathrm{C} / \mathrm{min}$ in a nitrogen purge gas from $25^{\circ} \mathrm{C}$ to $550^{\circ} \mathrm{C}$, the pan was kept isothermal for 3 minutes at this temperature. The sample was then cooled down to $300{ }^{\circ} \mathrm{C}$, meanwhile the gas was switched to oxygen and again raised heating rate $10^{\circ} \mathrm{C} / \mathrm{min}$ to $750{ }^{\circ} \mathrm{C}$. The flow rate for both nitrogen and oxygen gas was $90 \mathrm{ml} / \mathrm{min}$. The weight change as a function of temperature or time was recorded and analyzed. Figure 5 plots weight loss versus temperature and shows that around $8.5 \%$ of conductive particles were added to the PE matrix. Since all the particles have been combusted in the presence of the oxygen, this suggests that the conductive particle might be carbon black.

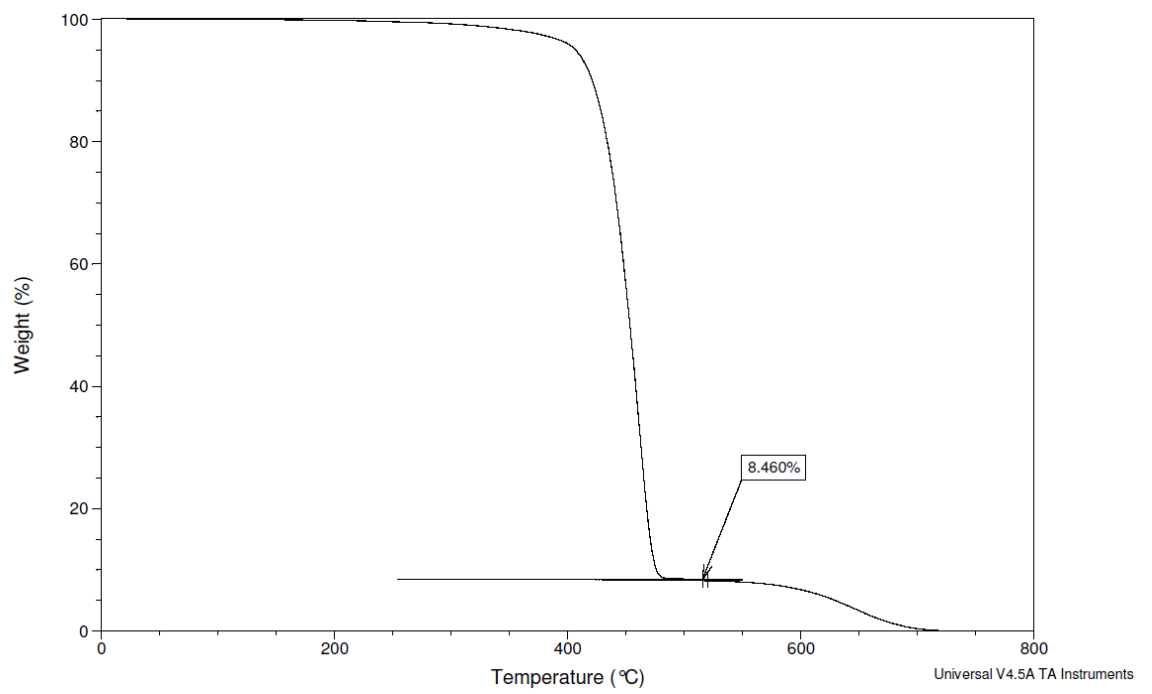

Figure 5 Thermogravimetric analysis of the pipe material, weight loss vs temperature

Usually adding particles like carbon black to the polymer to gain specific property can have significant side effects on other properties, (Huang, 2002) such as elongation at break, Charpy impact resistance and long-term properties under stress.

MuoviTech has filed the following two patents: 1) The TurboCollector, (Ojala et al. 2009), an innovation of the collector shape 2) Geothermal Pipe Collector, (Kalantar \& Skrifvars, 2013) enhancement of thermally-conductive PE composite.

The TurboCollector innovation, truly produces a unique inline extrusion process and micro fin design inside the geothermal pipe. This process, the die head orients melted material in hoop and axial direction, which vastly increases the pipe strength and toughness (Long et al., 1998; Nie, Bai \& Wang, 2010). In addition, twisting the micro fins promotes turbulent flow in the collector. The advantage of this innovation is, to reduce the flow rate with the same heat transfer rate (Acuna, 2010 and Acuna \& Palm, 2008).

Kalantar and Skrifvars have published several reports on the mechanical, thermophysical and rheological properties of the thermally-conductive composites in journal articles and conference proceeding (Mejrherjdi et al. 2013; Mehrjerdi et al. 2014; Kalantar, Ojala \& Skrifvars, 2015). Per these articles, the thermal conductivity and thermal diffusivity of the thermally-conductive $\mathrm{PE}$ composites are $0.7 \mathrm{~W} / \mathrm{m} .{ }^{\circ} \mathrm{K}$ and $1 \mathrm{~m}^{2} / \mathrm{s}$ respectively. 


\section{Numerical model simulation}

There are different numerical tools regarding the dimensioning of borehole heat exchangers, EED was used to simulate heat transfer associated with enhanced thermally conductive PE composites. EED requires the input of the design parameters of the ground, GHE, monthly heat loads and borehole field layout. Results obtained for the enhanced thermally conductive PE composites by Mehrjerdi et al. (2103) were used as input data in EED and the values were compared with the regular HDPE. Four different single U pipe configurations inside the groundwaterfilled borehole were investigated with the model to illustrate how concepts can be used. The properties and dimensions (outer diameter* wall thickness in $\mathrm{mm}$ ) of the pipes are given in Table 2. Synthetic building loads for a normal private house in Sweden were used with an average seasonal performance factor of 3 in the EED. Simulations were done for 25 years.

Table 2. Pipe Properties and Dimensions Used in the Numerical Model

\begin{tabular}{llcccc}
\hline Case & Thermal cond. & Thermal diff. & Spec. heat cap. & Density & Dimension \\
\hline \hline Case I & $0.4 \mathrm{~W} / \mathrm{m} . \mathrm{K}$ & $0.255 \mathrm{~m}^{2} / \mathrm{s}$ & $1.728 \mathrm{~J} / \mathrm{Kg} . \mathrm{K}$ & $0.953 \mathrm{~g} / \mathrm{cm}^{3}$ & $\varnothing 40 \mathrm{~mm} * 2.3 \mathrm{~mm} \mathrm{SDR} 17$ \\
Case II & $0.7 \mathrm{~W} / \mathrm{m} . \mathrm{K}$ & $1.026 \mathrm{~m}^{2} / \mathrm{s}$ & $0.5621 \mathrm{~J} / \mathrm{Kg} \cdot \mathrm{K}$ & $1.204 \mathrm{~g} / \mathrm{cm}^{3}$ & $\varnothing 40 \mathrm{~mm} 2.3 \mathrm{~mm}$ SDR 17 \\
Case III & $0.4 \mathrm{~W} / \mathrm{m} . \mathrm{K}$ & $0.255 \mathrm{~m}^{2} / \mathrm{s}$ & $1.728 \mathrm{~J} / \mathrm{Kg} . \mathrm{K}$ & $0.953 \mathrm{~g} / \mathrm{cm}^{3}$ & $\varnothing 40 \mathrm{~mm} * 3.6 \mathrm{mmSDR} 11$ \\
Case IV & $0.7 \mathrm{~W} / \mathrm{m} . \mathrm{K}$ & $1.026 \mathrm{~m}^{2} / \mathrm{s}$ & $0.5621 \mathrm{~J} / \mathrm{Kg} \cdot \mathrm{K}$ & $1.204 \mathrm{~g} / \mathrm{cm}^{3}$ & $\varnothing 40 \mathrm{~mm} * 3.6 \mathrm{~mm} \mathrm{SDR} 11$ \\
\hline
\end{tabular}

The output of the simulation program is the borehole length, the effective borehole resistance and mean temperature of the fluid at the end of month for the design period. Simulations were conducted for all four cases with Reynolds number $3000 \pm 100$, and to get comparable results, the effective borehole thermal resistance, pipe thermal resistance and the length of the borehole were determined. The summery of these results are shown in the table 3.

Table 3. Borehole Thermal resistance and Borehole Length Computed with EED for the Enhanced Thermally Conductive Material

\begin{tabular}{lccc} 
Case & $\begin{array}{c}\text { Borehole Thermal } \\
\text { Resistance }\end{array}$ & $\begin{array}{c}\text { Borehole } \\
\text { Length }\end{array}$ & $\begin{array}{c}\text { Pipe Thermal } \\
\text { Resistance }\end{array}$ \\
\hline \hline Case I & $0.1313 \mathrm{~m} . \mathrm{K} / \mathrm{W}$ & $147 \mathrm{~m}$ & $0.0486 \mathrm{~m} . \mathrm{K} / \mathrm{W}$ \\
Case II & $0.1179 \mathrm{~m} . \mathrm{K} / \mathrm{W}$ & $141.2 \mathrm{~m}$ & $0.0278 \mathrm{~m} . \mathrm{K} / \mathrm{W}$ \\
Case III & $0.1495 \mathrm{~m} . \mathrm{K} / \mathrm{W}$ & $154.8 \mathrm{~m}$ & $0.079 \mathrm{~m} . \mathrm{K} / \mathrm{W}$ \\
Case IV & $0.1285 \mathrm{~m} . \mathrm{K} / \mathrm{W}$ & $145.8 \mathrm{~m}$ & $0.0451 \mathrm{~m} . \mathrm{K} / \mathrm{W}$ \\
\hline
\end{tabular}

Simulations indicate that the effective borehole thermal resistance can be decreased when using thermally enhanced pipe in GHE with a single U bend. The lowest borehole resistance occurs for case II where the pipe with SDR 17 and thermally enhanced material was used. The thermally enhanced pipe reduces the borehole thermal resistance by $10 \%$ and $14 \%$ for the pipes SDR 17 and SDR 11 respectively. The reduction is greater for SDR 11 because the pipe has thicker wall thickness and the performance of the thermal conductive PE would be more effective. The borehole length required for a given system can be reduced by decreasing the borehole thermal resistance, therefore the length of the GHE can be decreased to reduce the total installation costs.

Raymond et al. (2011) have studied the performance of thermally enhanced pipes in vertical GHE systems. They have shown in a numerical modeling by COMSOL Multiphysics that the enhancement of the thermal conductivity of the pipe reduces the borehole thermal resistance by up to $24 \%$ for GHEs made with a single U-bend. They also made several thermal response tests and the measurement of the decrease in borehole thermal resistance associated with the thermally enhanced HDPE pipe is on the order of 20\% (Raymond et al., 2011). In fact, these simulations and in-situ thermal response test results are in good agreement with Figure 5. Due to an increase in the 
thermal conductivity of the material, the pipe thermal resistance reduces and accordingly the overall borehole resistance reduces.

\section{CONCLUSION}

Polyethylene with its broad spectrum of mechanical and thermophysical properties can be used in many applications. The key to its adaptability is due to its tuneable semicrystalline morphology, which can be controlled by the polymerization conditions and methodology. Research and development continue both the polymerization phase and post-polymerization processes with the goal of tailoring resins to meet the requirements of more specialized markets. The tailoring of polyethylene resins can be achieved either during polymerization, by regulating reaction conditions to affect branching and molecular weight, or by post-polymerization treatments such as compounding or blending. Good tensile strength, corrosion resistance, stiffness and long term slow crack resistance of new bimodal HDPE are desirable pipe attributes for water, sewer and natural gas distributions. Development efforts were not restricted to the polymerization processes; various fillers and fibers were added to the polymer to change the properties of the material. Only two efforts to enhance the thermal conductivity of the GHEs have been reported. Numerical analysis and in situ thermal response tests show that the enhancement of the thermal conductivity of the material can reduce significantly the overall borehole thermal resistance and BHE length. TurboCollector innovation of twisted fins improves the COP of the GSHP system and efficient energy consumption.

\section{ACKNOWLEDGEMENTS}

We are grateful to the MuoviTech International Group in Sweden, for their financial support and for allowing us to utilize the EED for this research study.

\section{REFERENCES}

Acuña, J. 2010. "Improvements of U-pipe borehole heat exchangers" Licentiate thesis, Royal Institute of Technology. Available online at: http://kth.diva-portal.org/smash/record.jsf?pid=diva2\%3A318637\&dswid=3075

Acuña, J. and B. Palm 2008. Experimental Comparison of Four Borehole Heat Exchangers. Refrigeration Science and Technology Proceedings Copenhagen. Available online at: http:/ / kth.diva-portal.org/smash/record.jsf?pid=diva2\%3A488591\&dswid=-41

Brömstrup H. 2009. PE 100 Pipe Systems - 3rd edition. Vulkan-Verlag GmbH publishing

Hellström G, Sanner B. 2016 Earth Energy Designer, Version 3.22. Department of Mathematical Physics, Lund University, Lund, Sweden and Lahnau, Germany,

Huang, J.-C. 2002. "Carbon black filled conducting polymers and polymer blends." Advances in Polymer Technology 21(4): 299-313.

Ojala, J. et al. 2008. "Collector "Us patent application nr. 12/733620

Kalantar, M.A. and Skrifvars M. 2013. "Geothermal Pipe Collector”. European patent application nr. 14112209.6

Kalantar, A., Ojala, K. and Skrifvars, M. 2015. Thermally enhanced pipe for low-temperature geothermal energy applications. 6th European Geothermal PhD Day, p.36 Available online at:

http://www.citg.tudelft.nl/fileadmin/Faculteit/CiTG/Actueel/Symposia_en_Congressen/6th_European_Geothermal _PhD_Day_2015/6th_EGPD_2015_Proceedings_m.pdf

Kissin Y. V. 2013. Polyethylene - End-use Properties and their Physical Meanings. Publisher: Hanser

Long, J., S. Kaizhi, J. Jiliang and G. Qing 1998. "A mandrel-rotating die to produce high-hoop-strength HDPE pipe by selfreinforcement." Journal of Applied Polymer Science 692): 323-328.

Malpass D.B. 2010. Introduction to Industrial Polyethylene - Properties, Catalysts, Processes, Wiley

Mehrjerdi, A.K., Adl-Zarrabi, B., Cho, S.W. and Skrifvars, M., 2013. Mechanical and thermo-physical properties of high-density polyethylene modified with talc. Journal of Applied Polymer Science, 129(4), pp.2128-2138.

Mehrjerdi, A.K., Mengistu, B.A., Åkesson, D. and Skrifvars, M., 2014. Effects of a titanate coupling agent on the mechanical and thermo-physical properties of talc-reinforced polyethylene compounds. Journal of Applied Polymer Science, 131(13). 
Nie, M., S. Bai and Q. Wang 2010. "High-density polyethylene pipe with high resistance to slow crack growth prepared via rotation extrusion." Polymer Bulletin 65(6): 609-621.

Peacock, A. 2000. Handbook of Polyethylene: Structures: Properties, and Applications, Taylor \& Francis.

Raymond J. et al. 2011. "A review of thermal response test analysis using pumping test concepts." Ground Water 49.6: 932945.

Raymond J. et al. 2011. "Numerical Modeling of Thermally Enhanced Pipe Performances in Vertical Ground Heat Exchangers." ASHRAE Transactions 117.1 2011.

Spitler J.D., S.J. Rees, and C. Yavuzturk 2000. Recent Developments in Ground Source Heat Pump System Design, Modelling and Applications. Proc. of CIBSE/ASHRAE joint conference "20 20 Vision", Dublin

Sundén, B. 2012. Introduction to Heat Transfer, WIT Press.

Syndicat, 2012. Principe de fonctionnement et usages de la géothermie, Syndicat des énergies renouvelables. Available online at:

http://www.enr.fr/userfiles/files/Kit\%20de\%20communication/2010104945_SERGothermie20100607LD.pdf

Vasile, C., and Pascu, M. 2005. Practical Guide to Polyethylene, Rapra technology

Versaprofiles , $2016:$ http://www.versaprofiles.com/en/products/file/geoperformx/16

Visakh P.M. and S. Lüft 2016. Polyethylene-Based Biocomposites and Bionanocomposites. John Wiley \& Sons.

White, J. R. and A. Turnbull 1994. "Weathering of polymers: mechanisms of degradation and stabilization, testing strategies and modelling." Journal of Materials Science 29(3): 584-613

Wypych G. 2009. Handbook of Fillers, 3 ed, ChemTec Publishing 